\title{
Research on industrialization path of educational robot
}

\author{
De-peng Kong ${ }^{1, a}$, Li-li Zhao ${ }^{2, b}$, Yi-fei Zhou ${ }^{3, c}$, Jiu-sheng Li.d \\ ${ }^{1,2,3,4}$ The Center of Robot Education Research, Zhejiang University of Technology,Hangzhou \\ 310023,China

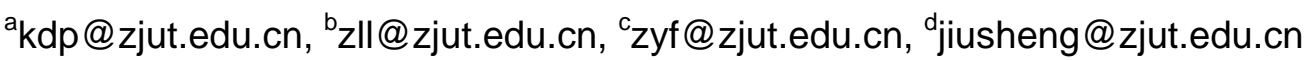

\begin{abstract}
Keywords: Educational robot, New format and new pattern, Industrialization path.
\end{abstract}
\begin{abstract}
With deep learning, cross-border integration and development of human-machine collaborative technology, artificial intelligence talent is in short supply, the intelligent education represented by education robot equipment in high-tech talent training and training plays a more and more important role, and with the development of information technology, people are constantly updated and iterative learning method, growing demand for teaching and education function increasingly prominent contradiction between robots is scarce, under the background of Internet + , based on the Internet of things, cloud computing and big data analysis of robot education new mode of the new industrialization path forms research has become a problem to be solved.
\end{abstract}

\section{Introduction}

Robot is one of the most creative inventions since twenty-first Century. Education robot develops teaching equipment based on teaching idea and teaching methods and teaching cases, and belongs to service robot in the early stage. There are some references to divide education robot into one category. It is not only the extension of industrial robot technology, but also the expansion of the function of the service machine and the diversification of the product. Reflect. After more than 20 years of development, educational robots have fully integrated technical, engineering, scientific and mathematical properties, that is, STEM attributes, and educational robots are one of the best carriers of STEM education. It has gradually entered various classes, laboratories and thousands of families, which are accepted and approved by the educational and parents. With the development of artificial intelligence technology, education robot needs to expand teaching resources and implement space, to complete deep relearning and complex teaching tasks, to achieve the goal of perfect auxiliary teaching, it also needs to strengthen STEM education, cultivate the ability of the learners, optimize the structure and quality of human resources, and improve the national competition,Force,Sterberg, a cognitive psychologist, proposed that the cultivation of success ability is the cornerstone of success in life[1], and the three elements of success are creativity, analytical and practical ability. In order to realize more expectation and function, education robot has a long way to go. Therefore, education robot combines big data, Internet of things and communication technology, and combines science and engineering depth to develop two times to promote the progress and perfection of the key technology of education robot. This is not only the robot in the age of artificial intelligence. The new requirements and new challenges posed by the "educational robot" branch is also a new way and new way to explore the training of compound talents of Engineering Science and technology in China.

\section{Research Status of Education Robot at Home and Abroad}

There are many research teams in the field of domestic robots. The research field not only focuses on the advanced planning of industrial robots, but also involves the research and development of service robots and educational robots. For example, Harbin Institute of Technology carries out robot related integration, human-computer interaction, intelligent technology and basic theory research. The Shenyang Institute of national sciences focuses on the research of robot thinking and action[2], perception and interaction, theory and method, and the innovation center of 
Beijing physical and technological intelligent robot, in the release of machinery, multiple control, A series of major frontier scientific problems have been solved in the field of multi-scale control and cross fusion, and the Institute of intelligent systems and control of Zhejiang University has research laboratories and research centers, such as "robotics". Zhejiang University of Technology has set up a Robot Cooperative Research Center, which plays the advantages of mechanical, electrical control and computer and electronic communication, and is committed to exploring the core issues of industrial robots and service robots. The Huang Renhuai team of Beijing Normal University founded the educational robotics Engineering Center in October 2015, taking the lead in the research and development of educational robots in related fields[4]. In the future, the technology of education robot and Internet of things will be integrated and inseparable. The process of robot industrialization is the process of enterprise service and technological innovation. The government and industry provide service for the transformation and upgrading of enterprises, meet the technical requirements of the intelligent manufacturing, and cultivate special technical skills talents in the field of the application field of the robot. It is also an important work. In 2016, the national science and technology personnel training project management center took the lead in approving the establishment of the national science and technology personnel training project robot research and development center, and standing for the development and application of the intelligent equipment for the Internet of things and robots. To train and train, collect the information of the robot, carry out real-time decision-making and control management, actively carry out international cooperation, enhance the competitiveness of the market, promote the industrialization of educational robots, and promote the all-round development of the robot transformation project.

\section{The Research Value of Educational Robot}

The research value of educational robot can be divided into two aspects: the first aspect is academic value. In addition to the knowledge of mechanical, electronic, information and sensing technology, educational robots can also cultivate technical application, problem solving, hands-on and team collaboration, and the ability to express and critical thinking. In the context of economic globalization, promoting the expansion and construction of innovative scientific and technological talents through robot education is a new way and a new model for the training of talents in our country. Therefore, on the premise of technology imparting, it is necessary to accelerate the study of relevant theories, academic discussions and training models, stimulate students' interest, guide students to think and deepen their thinking. The study of theory leading, understanding and talent training is the main research topic of education robot[5]. At the same time, how to use the Internet of things, cloud computing and block chain technology to realize the sharing of resources and to serve different levels of teaching, there are many problems to be further explored. In July 2017, the Zhejiang University of Technology set up a center for Robotics Education and research, giving full play to the advantages of electrical engineering, mechanical engineering and psychology. Combining teaching methods and curriculum theory, the ecological technology of educational robot resources sharing, the cultivation of robot compound talents and employment substitution, the ethics and education of educational robots are established. And other three research directions. The second aspect is the value of industrial research. Educational robot will open the new blue ocean of China's educational equipment market, open up the upstream and downstream industry chain, and combine the advantages of regional development, and the market prospect is huge. According to relevant information, the total sales volume of the global tablet computer in 2016 is 370 million, and the families with iPad purchasing ability are also able to buy Education robots. So it is conservative to estimate that the education robot family product is a new market more than about 8000000000 yuan per year. The education machine people replace the information technology to drive the education leap forward[6]. The time of the exhibition is coming. But China has no famous education robot brand, and foreign education robot brand enterprises, such as German fish, Danish Lego and Swiss LASY. Bill Gates has predicted that with the development of intelligent technology, intelligent robots will gradually replace personal computers and tablet computers and gradually 
integrate into the various fields of human life. Therefore, we need to quickly support our own brands and occupy the market at an early date.

\section{Research on the industrialization path of educational robot}

From the level of Chinese enterprise culture environment, national industrial polymerization and macro layout, it is necessary to make full investigation, carry out the correct industrial layout and positioning, create a characteristic industrial chain and form a characteristic industrial orientation by combining the industrial types, block characteristics, talent matching and policy advantages of the regional economy.

\section{(1) Speeding up the study of industry standards}

It is understood that the standard of industrial robot is relatively mature, but from the perspective of educational robot[7], no matter the foreign brand or the rising brand of China's independent research and development, there is a lack of standard and standard constraints adapted to it. We understand that education robot is a major product in the field of industrial subdivision. The research and formulation of a scientific and standardized standard system can promote the healthy development of the education robot industry. Therefore, it is difficult to speed up the research on the related standards of the education robot, and at the same time, it needs to rise to the national standard as soon as possible, thus leading the international standards, forcing the industry, providing the direction for the development of the industry, regulating and promoting the industrial development. The specific implementation process should follow the principles of the safety, availability, interoperability and traceability of educational robots, and establish and improve the basic generality, interconnection and intercommunication, industry application, network security, privacy protection and other technical standards research. Continue to study new technologies, such as induction technology, identification technology, control language, robot structure, wireless network, cloud technology and biomimetic technology, and other criteria for evaluation and judgment after the integration of educational robots, and explore the standard of system architecture, teaching platform management standards, mobile equipment and management terminal related standards. To make the standard system of educational robot more complete.

\section{(2)To improve the legal system of education robot}

Based on the integration of teaching practicality and technological innovation, educational robots adhere to the trend of internationalization and globalization, play the role of enterprises, industries, universities and scientific research institutes, and establish a complementary and flexible and efficient cooperative innovation system. The first is to explore the international rules, deepen the legal norms, construct the risk prevention and control mechanism and the early warning monitoring system, study the employment substitution and the social ethics and moral problems [6], based on the green health of education robot education, safe and reliable control, and benefit the people. The two is to study the organic combination and coordinated development of the robot education and teachers' professional posts, and to build the ethical characteristics of the education robot relying on the development of robot intelligent technology. Three is the different national boundaries, different cultures, social awareness and religious belief, which makes the ethical standards of the object of education robot service not the same. Of course, the basic rule is to concentrate the wisdom of the whole society and build on the basis of the democratic and fair health. The four is that in the process of use, the educational robot is a subject of responsibility. On the basis of following the moral rules, it has the basic cognitive ability of human beings, continuously implements the aim of "harmony", extends the ethical depth of the educational robot, and realizes the good coexistence of educational robots, teachers and students. For the education robot industry to develop and form regional competitive advantages, and better serve the "learner" goal, and continue to explore.

\section{(3) Build a cloud platform for robot education}

At present, educational robots not only distinguish between innovative and personalized service technology, but also can be applied to teaching resources. Because each manufacturer develops the resource platform based on its own technical level, it is incompatible with each other, different 
robots install different APP programs, and the designer designs the teaching resources from a single angle, and does not consider the demand of the public, which restricts the application and promotion of the products. Therefore, the research of robot education engineering technology is carried out. Starting from the standard formulation of education robot, the research of education service technology and the sharing service design of digital service resources, it is based on the independent knowledge brand[7], and promotes the industrialization development of scale and standard, and takes full consideration of the Internet of things, large data and cloud service technology. Sharing technology to improve the education robot and improve the function of education robot service technology and digital sharing resource platform to develop the urgent task, as early as a real person through oral interaction and passing ability, playing teachers, learning partners, assistant multiple angle color, and interactive and real-time users. Feedback, imitation of human brain in reasoning, proof and design, and other functions of thinking can be realized through intelligent cloud function.

\section{(4)Construction of educational robot industrial alliance}

With the emphasis on the commonness and key technology of the education robot industry, the independent innovation ability of the education robot industry is carried out, and the bottleneck problem of the servo system, controller, core algorithm, precision retarder and application and integration technology is solved, to conquer the common technical problems which have great influence on the education robot and to establish the educational machine. The platform of human industrialization service support, based on the industrial park, economic belt, or the region of the provinces and cities, set up a research center of education robot, industrial alliance or industry association, which is committed to the comprehensive development of production, research and research to serve the local economic development and develop the training and training of the robot education personnel from the national level[8]. Work, in the industry leading, industry positioning, talent training, standard formulation, technology innovation, product development, laboratory construction, curriculum system development, social services and so on to lead the healthy development of the robot industry, to solve the problem of insufficient supply of talent. At the same time, from the theoretical level, discipline system and standard research and development, we have carried out the work of personnel training system and platform construction.

\section{(5)Strengthening innovation and promoting demonstration}

According to the present situation of the development of artificial intelligence, it is necessary to dig out the needs of education robot in family service and educational application, to lay out an early layout of the characteristics of education robot equipment industry with Chinese characteristics. The way is to build an innovative platform, utilize and integrate scientific and technological resources and develop advantages, focus on frontier technology, and carry out teaching. The top-level design of the service standard and system of the education robot, the development of online service, the establishment of the integration system of authentication and detection, the improvement of the evaluation standards, the establishment of the national education robot evaluation and evaluation center[9], the development of the key components of the education robot and the system of the overall system testing instrument and instrument, and the implementation of the third party evaluation and certification plan. Encourage qualified enterprises to carry out brand building of educational robots, integrate regional industrial advantages, and form demonstration industry application engineering.

\section{(6) Integrate resources and strengthen overall planning}

To promote the healthy development of the education robot industry, it not only needs the local government to carry out the correct industrial orientation, but also needs the cooperation and support of various functional departments, such as the development reform, the industrial management, the scientific and technological services and the financial and tax departments. The first is to make use of the central fund and fund support policy, seize the major technical equipment insurance compensation and tax exemption policy[10], encourage enterprises to increase capital investment, improve the level of scientific and technological production, play the role of tariff 
dynamic protection and preferential measures, use diversified investment and financing channels, support teaching with the help of banks and funds within the scope of business. The advantages of robot breeding are to develop enterprises at home and abroad, including investment and financing, mergers and acquisitions and listing. The two is to use the policy of living industry well, to develop the industrial cluster of education robot in the place where there is conditions, environment and strength, and to guide the aggregation and concentration of the production factors and the industrial chain.

\section{Conclusion}

Through the discussion of the industrialization path of education robot, the educational and service functions of education robot are more and more complete. No matter the educators are still in the product manufacturers, even the learners, they all understand and understand the educational robot systematically, and clarify the product attributes of the education robot. The characteristics of industry and the feasibility of industrialization not only help the local education robot to take root, but also promote the local transformation of foreign and foreign brands, provide more targeted Chinese education robot products, resources and even after-sales service, improve the cost performance of products and promote robot assisted educationt. At the same time, the better industrialization path analysis and research can provide decision-making and reference for the government's decision-making and industrial layout.The educational robot industrial base of color forms the industrial cluster with Chinese characteristics.

\section{Acknowledgement}

In this paper, the research was sponsored by The public welfare project of Zhejiang province (NO.2015C35004:Research on the evolution mechanism of the new format of industrial development under the cloud manufacturing service mode) and Humanities and Social Sciences projects of the Ministry of Education (NO.14YJCZH067:The digital resources of vocational education are out of line with users' needs and Adjustment Research) and Zhejiang's philosophy and Social Sciences Planning Project (NO.15NDJC164YB).

\section{References}

[1] Cao Xiangkang. Reflections on the industrialization of industrial robots [J]. robot technology and Application, 2000(3):4-7.

[2] Li Ruifeng. China's industrial robot industrialization development strategy [J].aviation manufacturing technology, 2010(35709):32-37.

[3] In the next five years, robot development will focus on ten major issues. The robot industry development plan (2016-2020 years)[J].China's strategic emerging industries, 2016 (11): 44-45.

[4] Huang Ronghuai, Liu Dejian. Development status and trend of educational robotics [J]. modern educational technology, 2017,27 (01): 13-20.

[5] Du Zhong.In the next five years, robot development will focus on ten major issues. The robot industry development plan (2016-2020 years) [J]. China's strategic emerging industries, 2016 (11): 44-45.

[6] Zhang Hongxia, Chen Xiaohang. Problems and Countermeasures of industrial robot industrialization development [J]. technology wind,2015(27719):214-221.

[7] Ministry of science and technology. Six departments jointly issued the "guiding opinions on promoting the construction of strategic alliance of industrial technology 
innovation".[EB/OL].http://www.most.gov.cn/yw/200902/t20090220_67551.htm.2009-02-21.

[8] Wang Yue ya. Key downstream application market demand for explosion-proof security enhancement [J]. China security.2013 (4): 55-58.

[9] China will issue robot inspection and certification mark, service robot or compulsory certification.[EB/OL].http://news.163.com/16/1014/19/C3C40MVU000187VE.html.2016-1014.

[10]Wang Yuechao. Speed up the construction of robot industrialization base, enhance the competitiveness of Liaoning's equipment manufacturing industry [J]. China's manufacturing informatization,2003(05):35-36. 